\title{
Effect of Intercostal Stretch and Breathing Control Exercise on Lung Function among Healthy Young Females
}

\author{
Deepshikha Trivedi ${ }^{1}$, Arijit Kumar Das ${ }^{2}$ \\ ${ }^{1}$ Assistant Professor, St. Andrews College Physiotherapy, Pune, Maharashtra, India. \\ ${ }^{2}$ Associate Professor, Dr. Vithalrao Vikhe Patil College Physiotherapy, Ahmednagar, Maharashtra, India. \\ Corresponding Author: Deepshikha Trivedi
}

DOI: https://doi.org/10.52403/ijhsr.20220208

\begin{abstract}
Introduction: Intercostal (IC) muscles help in upward and outward movement of the ribs which results in increase in antero-posterior diameter of the thoracic cavity. The use of manual stretching procedure is prevalent in respiratory physiotherapy to improve pulmonary functions.

Objective: To determine the effect of Intercostal (IC) stretch and breathing control in improving the lung function parameters (Forced Expiratory Volume) in the first second (FEV1), Forced Vital Capacity (FVC) and FEV1/FVC \% and respiratory rate among healthy young females.

Methodology: Thirty healthy female subjects, age 19-24 years were recruited based on inclusion and exclusion criteria and written informed consent was taken. Participant's assessment and evaluation was done. Lung function parameters and respiratory rate were recorded before undergoing procedure. Subjects underwent three IC stretch for ten breaths on the inspiratory phase of the respiratory cycle followed by breathing control exercises with a time gap of 2-3 minutes in semi recumbent position. Immediately, following intervention, the respiratory rates recorded and lung function test were performed using spirometry to evaluate the effect of intervention. The total sessions last for 15 minutes.

Result: By applying Paired t-test for Pre and Post values of FEV1, FVC, FEV1/FVC and respiratory rate $\mathrm{p}$-value obtained was 0.0001 , which was statistically significant. This suggested that IC stretching with breathing control is more effective in improving dynamic lung parameters.

Conclusion: The study concludes that there was a significant improvement in the lung function (FVC, FEV1, FEV1/FVC) and respiratory rate among the healthy young females who underwent IC stretch followed by breathing control exercise.
\end{abstract}

Keywords: Intercostal Stretch, Breathing Exercises, Lung Function Parameters.

\section{INTRODUCTION}

The respiratory system consists primarily of the lungs, whose main function is to ensure gas exchanges with the environment, and the thoracic wall, which moves as a result of continual muscle action $^{1}$. The thoracic wall represents the thoraco-abdominal area composed of the rib cage and the abdomen, separated by the diaphragm ${ }^{2,3}$. Thus, normal thoracoabdominal motion consists of expansion and retraction of these compartments during inspiration and expiration, respectively ${ }^{4,5}$.

Breathing pattern and thoracoabdominal motion may be influenced by several factors, such as the individual's positioning ${ }^{6,7}, \quad \operatorname{age}^{7,8}, \quad \operatorname{sex}^{7}, \quad$ respiratory overload $^{9}$, neuromuscular diseases ${ }^{10}$, lung diseases associated with increased airway resistance ${ }^{4,11,12}$ and chronic obstructive pulmonary disease $(\mathrm{COPD})^{5,13-15}$. Higher rates of asynchrony may be related to worse 
prognosis and significantly greater mortality ${ }^{13}$.

Although the rib cage and abdomen move in unison, each of the compartments has independence of movement ${ }^{16}$. When the displacement between the compartments ceases to be harmonious, the thoracoabdominal motion becomes asynchronous 4,5,17. Healthy men and women in different age groups present symmetry between the movements on the right and left sides of the chest and abdomen ${ }^{18}$.

In relation to sex, a study that made comparisons between men and women showed that there were differences in respiratory times ${ }^{3}$. The inspiratory time, expiratory time, and total time of the respiratory cycle were shorter among the women. In addition, the women presented higher respiratory frequency, thus suggesting that they tended to breathe more rapidly than the men. In the analysis of thoraco-abdominal motion during quiet breathing, men and women presented the same response $\mathrm{e}^{3,7}$.

Intercostal (IC) muscles are diverse and widely spread throughout the rib cage. These muscles help in upward and outward movement of the ribs which results in increase in antero-posterior diameter of the thoracic cavity ${ }^{19}$. The IC muscles help both in inspiration and forced expiration.

Even though these muscles engage in respiration their activities are fewer during active contraction among normal healthy adults ${ }^{20}$. Various research studies demonstrated that IC stretching improved expired tidal volume, decreased the level of dyspnea and increased chest expansion clinically which results in better gaseous exchange in human subjects ${ }^{21,22}$.

IC stretch is performed actively by thoracic mobility exercises. Passively IC stretch can be performed by thoracic rotation, midsternum rotation, lateral thoracic stretching, through thoracic mobility exercises as well as through manual stretching of IC spaces ${ }^{21}$

The external IC muscles which are helpful during inspiration showed a higher discharge activity during forcible inhalation. Similarly, a stretch of 15 micrometers applied to IC spaces showed an increase in muscle activity in cats ${ }^{23}$. The increase in muscle activity of the IC muscles could lead to increase in lung volume and capacities.

According to Puckree $^{24}$, IC stretching and controlled breathing is effective in improving breathing pattern and respiratory muscle activity among healthy conscious adults. However; none of the research studies examined the effect of IC stretching on dynamic pulmonary function parameters among healthy subjects. Morphologically intercostal muscles displayed a variation in fiber size and atrophy among obstructive lung disease subjects ${ }^{25}$.

Hence, a change in pulmonary function parameters while performing IC stretching and controlled breathing might benefit to a particular population where respiratory compromise has been demonstrated due to poor IC muscle function. Therefore, the main purpose of the study was to observe the effect of IC stretching and controlled breathing on pulmonary function parameters.

\section{PROCEDURE}

Patients selected for the project were explained about the study and written consent was taken from them.

Respiratory rate Before participation, all subjects underwent resting respiratory rate measurement. Initially the study subjects were requested to lie on a semi recumbent position and readings taken after 3 minutes of resting using auscultation methods. The method adopted in this study to measure respiratory rate was reliable according to a protocol described earlier ${ }^{26}$.

Pulmonary function test The ventilator parameters such as forced expiratory volume in 1st second (FEV1), forced vital capacity (FVC) and forced expiratory volume in first second percentage (FEV1\%), were measured by pulmonary function test. A pulmonary function test was carried out by using the handheld spirometer to 
estimate the dynamic lung function parameters. Participant's details were taken before pulmonary function testing such as age; height and weight using SECA weight and height scale (Vogel \& Halke, Hamburg, Germany). Then, the variables were keyed into the Pony Fx Cosmed, Italy, spirometer ${ }^{27}$. According to the (ATS)/(ERS) task force ${ }^{28}$, spirometry training and testing were performed to ensure quality. Testing was carried out in sitting position and rest interspersed between each of the three tests. The participants were requested to perform at least three trails and the best of the three values for the manoeuvre such as slow vital capacity and forced vital capacity was taken by the same physiotherapist as suggested by ATS/ERS task force ${ }^{28}$. The spirometry test was preceded with IC stretch.

IC stretch and breathing control Initially a stretch was applied by the same physiotherapist on the left-side midway between the midaxillary line and a line through the nipple in the downward direction of the third IC space. The IC stretch was applied by the physiotherapist manually with the help of index finger over the third IC spaces in a caudad - cephalad direction to the upper borders of the fourth $\mathrm{rib}^{24}$. Enough care was paid to avoid compression of the chest wall. Breathing control exercises were performed followed by IC stretching. This was performed in a comfortable semi recumbent position with a pillow under both knees. Participants were encouraged to place their hands over the upper abdomen. As the subject breathed in, the hands were placed over the epigastric region to feel the rise; as they breathed out, the hand sank ${ }^{29}$.

Immediately,

following intervention, the respiratory rates recorded and pulmonary function test were performed using spirometry to evaluate the effect of intervention. Subjects underwent three IC stretch and breathing control exercises with a time gap of 2-3 minutes. Each stretch was employed for ten breaths throughout the inspiratory phase of the respiratory cycle. minutes.

The total sessions last for 15

\section{RESULT}

Table 1: Pre and Post Mean \pm Standard Deviation (SD) of FEV $_{1}$ Values

\begin{tabular}{|l|c|}
\hline FEV $_{1}$ Values & Mean \pm SD \\
\hline Pre - Intervention & $1.90 \pm 0.29$ \\
\hline Post - Intervention & $2.17 \pm 0.24$ \\
\hline
\end{tabular}

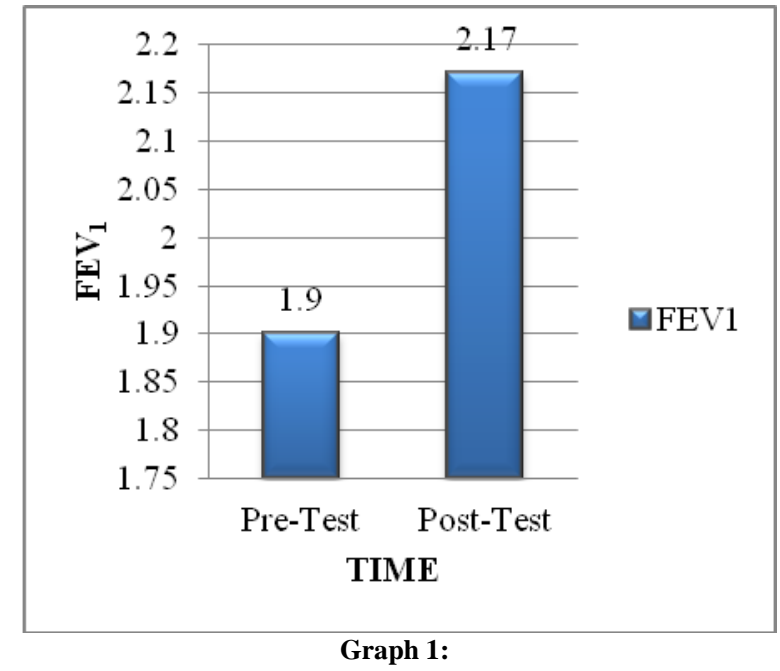

INFERENCE: The graph shows significant difference in the Pre-test and Post-test values. $\mathrm{FEV}_{1}$ values, indicating that the Post-test value is more than Pre-test value $(\mathrm{t}$ $=-7.96, \mathrm{p}=0.0001$ )

Table 2: Pre and Post Mean \pm Standard Deviation of FVC Values

\begin{tabular}{|l|c|}
\hline FVC Values & Mean \pm SD \\
\hline Pre - Intervention & $2.01 \pm 0.27$ \\
\hline Post - Intervention & $2.29 \pm 0.26$ \\
\hline
\end{tabular}

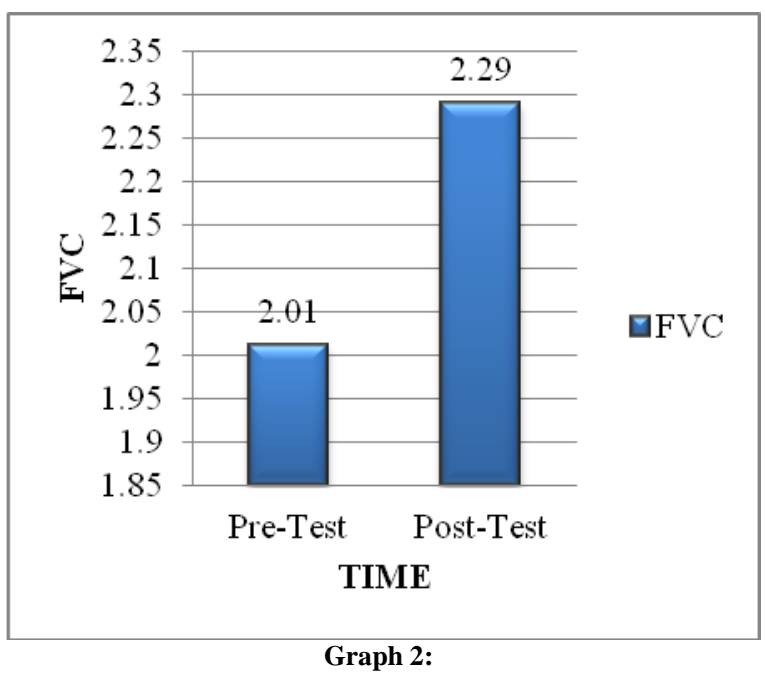


INFERENCE: This graph shows a significant increase in FVC values after the IC stretch and breathing control exercise which indicates that the post-test values are greater than pre-test values $(\mathrm{t}=4.14, \mathrm{p}=$ $0.001)$

Table 3: Pre and Post Mean \pm Standard Deviation of FEV $_{1}$ /FVC Values

\begin{tabular}{|l|c|}
\hline FEV $_{1} /$ FVC Values & Mean \pm SD \\
\hline Pre - Intervention & $94.11 \pm 3.20$ \\
\hline Post - Intervention & $95.16 \pm 3.026$ \\
\hline
\end{tabular}

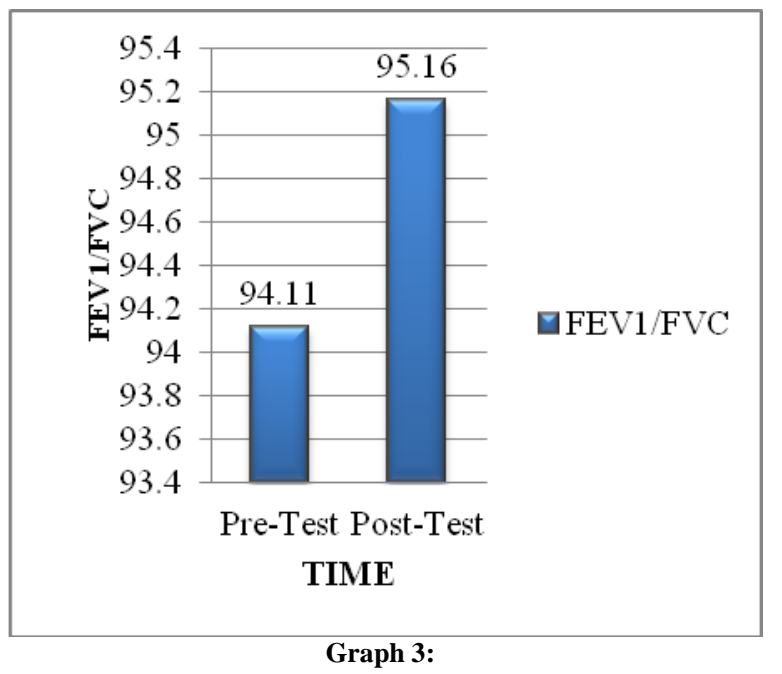

INFERENCE: There was also increase in the post-test $\mathrm{FEV}_{1} / \mathrm{FVC}$ ratio, indicating post-test values are more than pre-test values $(\mathrm{t}=-4.363, \mathrm{p}=0.001)$

Table 4: Pre and Post Mean \pm Standard Deviation of Respiratory rate

\begin{tabular}{|l|c|}
\hline Respiratory rate & Mean \pm SD \\
\hline Pre - Intervention & $19.3 \pm 0.33$ \\
\hline Post - Intervention & $18.2 \pm 0.32$ \\
\hline
\end{tabular}

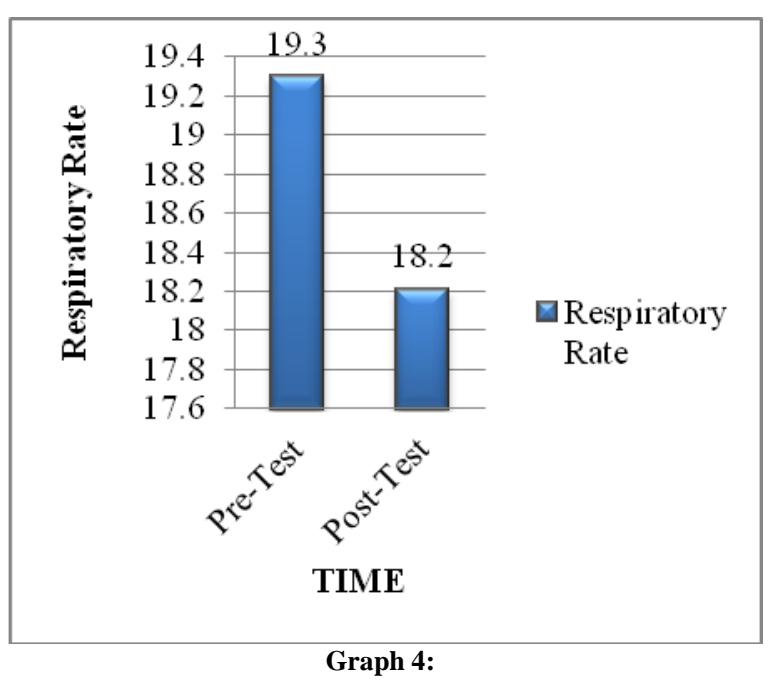

INFERENCE: The comparison of pre and post test values of respiratory rate showed the lowered respiratory rate in post intervention test $(\mathrm{t}=4.52, \mathrm{p}=0.0001)$

\section{DISCUSSION}

This study was done to find out the effect of Intercostal stretch and breathing control exercise on lung function among 15 healthy young females in the age group of 19-24 years. The subjects were taken from Dr. D.Y. Patil college of Physiotherapy, Pimpri, Pune.

The findings of this study showed the improvement in lung function $\left(\mathrm{FEV}_{1}\right.$, $\mathrm{FVC}, \mathrm{FEV}_{1} / \mathrm{FVC}$ ) and respiratory rate among healthy conscious females who were given IC stretch with breathing control exercises.

The result of this study shows a significant increase in the lung function post IC stretch and breathing control exercise. The overall increase in mean post treatment values were $\mathrm{FEV}_{1}=2.17 \pm 0.24, \mathrm{FVC}=$ $2.29 \pm 0.26, \mathrm{FEV}_{1} / \mathrm{FVC}=95.16 \pm 3.02$.

The changes in lung function is due to the firing discharged from the muscle spindle during a passive stretch phase $\mathrm{e}^{20}$. IC stretching activates the stretch receptors in the chest wall, thereby distending thorax which could be neurologically linked to medulla with efferent nerve cells. The afferents, that innervate the margins of diaphragm activates the reflex which alters the pulmonary parameters ${ }^{29}$.

The IC enhances the chest wall elevation and thereby increases the expansion by improving intra-thoracic lung volume which contributes to improve the flow rate percentage. This may contribute in increasing the ventilatory capacity (tidal volume), minute ventilation and oxygen status $^{31 .}$

As studied by Threlkeld $^{32}$ by applying manual techniques such as IC stretch produces a suitable amount of plastic deformation of connective tissue which enhances mobility at joints. Therefore, the result of this study suggests that IC stretch was an effective treatment parameter. 
There is increase in the value of lung function post IC stretch and breathing exercise which indicates improvement in the lung function. It can be due to the semirecumbent position during the breathing exercise as in this position there is posterior pelvic tilt and gravity assist the diaphragm in functioning effectively in its role as the primary muscle of inspiration.

There is also significant decrease in the respiratory rate post IC stretch and breathing control exercise (respiratory rate $=$ $18.2 \pm 0.32$ ). The rate of respiration is lowered, as the semi-recumbent position during breathing control exercise helps to improve tidal volume and lowers the respiratory rate $^{33}$. As this position gives mechanical advantage by decreasing the pressure of the abdominal organs over the diaphragm and helps the diaphragm to work efficiently thereby increasing the chest expansion and giving more space for the lung volumes. This may be one of the reasons for the significant improvement seen post breathing control exercises along with IC stretch over the taken lung function parameters.

Few studies have proven the improvement in the breathing pattern can be due to localized stretch in the third ICs, showing a deeper breathing pattern, greater activities on parasternal ICs, electromyographic activities which resulted in an increase in tidal volume and a decrease in breathing frequency among healthy subjects $^{24}$.

A possible limitation of the study was quantification of stretch pressure was not performed and it's uncertain how far these stretch receptors stimulated to evoke response. The sample size of the study was very low with very short duration of the study.

\section{CONCLUSION}

The study concludes that there was a significant improvement in the lung function (FVC, FEV, $\mathrm{FEV}_{1} / \mathrm{FVC}$ ) and respiratory rate among the healthy young females who underwent IC stretch followed by breathing control exercise.

\section{Acknowledgement: None}

\section{Conflict of Interest: None}

\section{Source of Funding: None}

\section{Ethical Approval: Approved}

\section{REFERENCES}

1. Macklem PT. Clinical assessment on the respiratory muscles. Pneumonol Pol. 1988;56(6):249-53.

2. De Troyer A, Estenne M. Functional anatomy of the respiratory muscles. Clin Chest Med. 1988;9(2):175-93.

3. Feltrim M. Estudo do padrão respiratório e da configuração toracoabdominal em indivíduos normais, nas posições sentada, dorsal e laterais, com o uso da pletismografia por indutância [dissertação]. São Paulo (SP): Universidade Federal de São Paulo; 1994.

4. Kiciman NM, Andreasson B, Bernstein G, Mannino FL, Rich W, Henderson C, et al. Thoracoabdominal motion in newborns during ventilation delivered by endotracheal tube or nasal prongs. Pediatr Pulmonol. 1998;25(3):175-81.

5. Sackner MA, Gonzalez H, Rodriguez M, Belsito A, Sackner DR, Grenvik S. Assessment of asynchronous and paradoxic motion between rib cage and abdomen in normal subjects and in patients with chronic obstructive pulmonary disease. Am Rev Respir Dis.1984;130(4):588-93.

6. Maynard V, Bignall S, Kitchen S. Effect of positioning on respiratory synchrony in non-ventilated pre-term infants. Physiother Res Int. 2000;5(2):96-110.

7. Verschakelen JA, Demedts MG. Normal thoracoabdominal motions. Influence of sex, age, posture, and breath size. Am J Respir Crit Care Med. 1995;151(2 Pt 1):399-405.

8. Britto RR, Vieira DSR, Rodrigues JM, Prado LF, Parreira VF. Comparação do padrão respiratorio em adultos e idosos. Rev Bras Fisioter. 2005;9(3):281-7. 
9. Tobin MJ, Perez W, Guenther SM, Lodato RF, Dantzker DR. Does rib cageabdominal paradox signify respiratory muscle fatigue? J Appl Physiol. 1987; 63(2): 851-60.

10. Perez T, Becquart LA, Stach B, Wallaert $\mathrm{B}$, Tonnel AB. Inspiratory muscle strength and endurance in steroid-dependent asthma. Am J Respir Crit Car Med. 1996;153(2):610-5.

11. Allen JL, Wolfson MR, McDowell K, Shaffer TH. Thoracoabdominal asynchrony in infants with airflow obstruction. Am Rev Respir Dis. 1990; 141(2):337-42.

12. Rusconi F, Gagliardi L, Aston H, Silverman M. Respiratory inductive plethysmograph in the evaluation of lower airway obstruction during methacholine challenge in infants. Pediatr Pulmonol. 1995;20(6):396-402.

13. Ashutosh K, Gilbert R, Auchincloss JH Jr, Peppi D. Asynchronous breathing movements in patients with chronic obstructive pulmonary disease. Chest. 1975;67(5):553-7.

14. Delgado HR, Braun SR, Skatrud JB, Reddan WG, Pegelow DF. Chest wall and abdominal motion during exercise in patients with chronic obstructive pulmonary disease. Am Rev Respir Dis. 1982;126(2):200-5.

15. Sharp JT, Goldberg NB, Druz WS, Fishman HC, Danon J. Thoracoabdominal motion in chronic obstructive pulmonary disease. Am Rev Respir Dis. 1977; 115(1):47-56.

16. Konno K, Mead J. Measurement of the separate volume changes of rib cage and abdomen during breathing. J Appl Physiol. 1967;22(3):407-22.

17. Tobin MJ, Chadha TS, Jenouri G, Birch SJ, Gazeroglu HB, Sackner MA. Breathing patterns. Normal subjects. Chest. 1983;84(2):202-5.

18. Ragnarsdottir M, Kristinsdottir EK. Breathing movements and breathing patterns among healthy men and women 20-69 years of age. Reference values. Respiration.2006;73(1):48-54.
19. De Troyer A, Kirkwood PA, Wilson TA. Respiratory action of the IC muscles. Physiol Rev 2005; 85:717-56.

20. Hirai N, Ichikawa T, Miyashita M. Activity of the IC muscle spindle afferents in the lower thoracic segments during spontaneous breathing in the cat. Neurosci Res 1996; 25:301-4.

21. Leelarungrayub D, Pothongsunun $P$, Yankai A, Pratanaphon S. Acute clinical benefits of chest wall-stretching exercise on expired tidal volume, dyspnea and chest expansion in a patient with chronic obstructive pulmonary disease: a single case study. J Bodyw Mov Ther 2009; 13:338-43.

22. Bethune DD. Neurophysiological facilitation of respiration in the unconscious adult patient. Physiotherapy Canada 1975; 27:241-6.

23. Bolser DC, Lindsey BG, Shannon R. Medullary inspiratory activity: Influence of IC tendon organs and muscle spindle endings. J Appl Physiol 1987; 62:104656.

24. Puckree T, Cerny T, Bishop B. Does IC stretch alter breathing pattern and respiratory muscle activity in conscious adults? Physiotherapy 2002; 88:89-97.

25. Campbell JA, Hughes RL, Sahgal V, Frederiksen J, Shields TW. Alterations in intercostals muscle morphology and biochemistry in patients with obstructive lung disease. Am Rev Respir Dis 1980; 122:679-86.

26. Edmonds ZV, Mower WR, Lovato LM, Lomeli R. The reliability of vital sign measurements. Ann Emerg Med 2002; 39:233-7.

27. Ngai SP, Jones AY, Hui-Chan CW, Ko FW, Hui DS. Effect of Acu-TENS on postexercise expiratory lung volume in subjects with asthma-A randomized controlled trial. Respir Physiol Neurobiol 2009; 167:348-53.

28. a) Miller MR, Hankinson J, Brusasco V, Burgos F, Casaburi R, Coates A et al.; ATS/ ERS Task Force. General considerations for lung function testing. Eur Respir J 2005a; 26:153-61.

b) Miller MR, Hankinson J, Brusasco V, Burgos F, Casaburi R, Coates A et al.; 
ATS/ERS Task Force. Standardisation of spirometry. Eur Respir J 2005b; 26:31938.

29. Jennifer A, Pryor SAP. Physiotherapy for respiratory and cardiac problems: adults and paediatrics ( $\mathrm{pp}$ 143-73). London: Churchill Livingston, 2008.

30. Mohan V, Henry LJ, Roslizawati N, Das S, Kurup M, Gopinath B. Effect of unsupported arm exercises on spirometry values and functional exercise tolerance of subjects with chronic obstructive pulmonary disease. Int Med J 2010; 17:113-6.

31. Chang A, Paratz J, Rollston J. Ventilatory effects of neurophysiological facilitation passive movement in patients with neurological injury. Aust $\mathrm{J}$ Physiother 2002;48: 305-10.

32. Threlkeld AJ. The effects of manual therapy on connective tissue. Phys Ther 1992; 72:893-902.

33. Burns SM, Egloff MB, Ryan B, Carpenter R. Effect of body position on spontaneous respiratory rate and tidal volume in patients with obesity, abdominal distension and ascites. Am J Crit Care. 1994 Mar;3(2):102-6.

How to cite this article: Trivedi D, Das AK. Effect of intercostal stretch and breathing control exercise on lung function among healthy young females. Int $J$ Health Sci Res. 2022; 12(2): 64-70. DOI: https://doi.org/10. 52403/ijhsr.20220208 